\title{
Forum on Race and Genomics
}

'All of this study of genotypes will have profound consequences on our understanding of race and ethnicity', Francis Collins, Director of the National Human Genome Research Institute, warned his colleagues in 2003. At BioSocieties, we have been committed to bringing the perspectives of the social sciences to bear on the charged issues at hand. In September 2006 (Vol. 1, Part 3), we published our first forum on race and genomics, where we focused on larger questions raised by the decision of Nature Genetics to publish a special openaccess supplement-Genetics for the Human Race-in November 2004, concerned with the topic of human genome variation and the continuing validity of the concept of 'race'. In the forum, sociologist Andrew Smart and colleagues analysed the contributions to that supplement, as well as interview material from the three editors behind it, to tease out the larger methodological, scientific and ethical dilemmas that scientists in the thick of genomics and race research perceived themselves to face. Charmaine D.M. Royal, one of the contributors to Genetics for the Human Race, then responded to the issues raised by Smart and colleagues.

There is more, however, to say about these matters-much more. Here, we continue the discussion with a second forum that showcases three other pieces of scholarship that we believe can help begin to move the debate beyond its usual binary choice of being 'for' or 'against' references to race in genomics and genetic biomedicine. We do this with a contribution from Duana Fullwiley, who uses ethnographic observation and rich interview material to illuminate ways in which scientists navigate for themselves the keenly felt uncertainties and complexities of genomic research that is focused on human difference. Jenny Reardon further charts some of this uncertainty and complexity through her study of the strategies used in the International HapMap Project to define its sample populations and to seek democratic legitimacy for their involvement: population genetics is involved in making up and transforming, the very 'people', individual and collective, on which democracy rests its claims to legitimacy. And, in his contribution, anthropologist Gísli Pálsson, takes a broad multicultural perspective to show how everything from the genetics of birthmarks to fingerprints can be 'marked' with racial meaning.

We expect to continue to solicit scholarship and commentary on these important issues; and we welcome responses from our readers. 